\title{
LOCALIZATION AND CHARACTERIZATION OF GASTRIN/ CHOLECYSTOKININ-LIKE IMMUNOREACTIVITY IN THE CENTRAL NERVOUS SYSTEM OF APLYSIA CALIFORNICA ${ }^{1}$
}

\author{
STEVEN R. VIGNA, ${ }^{2}$ JAMES L. M. MORGAN, ${ }^{3}$ AND THEA M. THOMAS \\ Department of Biology, University of Oregon, Eugene, Oregon 97403
}

Received September 2, 1983; Revised January 9, 1984; Accepted January 10, 1984

\begin{abstract}
Gastrin/cholecystokinin-like immunoreactivity (G/CCK-LI) was localized by immunocytochemistry in neurons in the central nervous system of Aplysia californica. Neuronal cell bodies were specifically immunostained in the buccal, cerebral, pedal, and abdominal ganglia but not in the pleural ganglia. Neural G/CCK-LI processes were observed in the neuropil of all ganglia and connectives and in some but not all of the peripheral nerves examined. Somata containing G/CCKLI ranged from 15 to $200 \mu \mathrm{m}$ in diameter. Ganglionic G/CCK-LI was most efficiently extracted in neutral or basic solutions and consisted mainly of a substance eluting in a volume corresponding to a peptide of between 8 and 17 amino acid residues on gel filtration. This G/CCK-LI diluted in parallel to mammalian gastrin in radioimmunoassays using two antisera differing in their specificities for the bioactive $\mathrm{COOH}$-terminal region of mammalian G/CCK. We conclude that G/CCK-LI is distributed widely in the central and peripheral nervous systems of Aplysia californica and that this immunoreactivity probably represents a small peptide which is similar but not identical to mammalian gastrins and cholecystokinins at the functionally critical $\mathrm{COOH}$ terminus.
\end{abstract}

Mammalian gastrin and cholecystokinin (CCK) are regulatory peptides which were first described as gastrointestinal hormones and subsequently shown to be neuropeptides as well (Rehfeld, 1981). Gastrin and CCK are structurally related at their $\mathrm{COOH}$-terminal active sites, and thus their biological activities overlap pharmacologically (Ondetti et al., 1970). Cholecystokinin is distributed in a broad rostral to caudal gradient in the mammalian brain. Highest concentrations are found in the cerebral cortex; intermediate concentrations are found in the thalamus, hypothalamus, and hippocampus; and very little is found in the cerebellum and hindbrain (Williams, 1982). Brain CCK is notable not only for its unusual distribution compared to most other peptides, but also because it is present in amounts far higher than other known neuropeptides (Rehfeld, 1980). In the mammalian brain, gastrin is present only in the hypophysis

\footnotetext{
${ }^{1}$ We thank Dr. J. W. Crim, University of Georgia, for advice about immunocytochemistry, and Drs. G. J. Dockray, University of Liverpool, G. L. Rosenquist, University of California, Davis, and J. H. Walsh, University of California, Los Angeles, for generous gifts of antisera. This work was supported by grants from the Medical Research Foundation of Oregon and National Science Foundation Grant PCM 8104338 to S. R. V.

${ }^{2}$ To whom reprint requests should be addressed.

${ }^{3}$ Present address: Department of Zoology, Oregon State University, Corvallis, OR 97331.
}

of certain species (Rehfeld, 1978). Although many possible actions of CCK in the brain have been described, such as mediation of satiety, pituitary regulation, analgesia, and others (for reviews, see Dockray, 1982; Williams, 1982), little is known about the physiological role of the peptide in CNS function. Nothing seems to be known about the function of hypophysial gastrin.

A factor with immunochemical properties resembling those of gastrin has been described in gut extracts and hemolymph of the marine gastropod mollusc, Aplysia californica (Straus et al., 1975). In a recent survey of gastrin/CCK (G/CCK)-like peptides in invertebrates, we confirmed this finding and added the central nervous system as a source of extractable G/CCK-like immunoreactivity (G/CCK-LI) in Aplysia (Larson and Vigna, 1983). Gastrin/CCK-like peptides have also been reported in the nervous systems of the molluscs Lymnaea stagnalis (Schot et al., 1981) and Helix aspersa (Osborne et al., 1982). Although few species have been examined, it seems likely that molluscs share with mammals and perhaps many other animal taxa the utilization of CCK or a related peptide in CNS function. In view of the present ignorance regarding the physiological role of CCK or gastrin in any nervous system, it seems likely that study of G/CCK in the relatively simple CNS of Aplysia may illuminate some features of the neurobiology of these peptides. 
In the present communication, we describe the cellular source and some immunochemical properties of $\mathrm{G} / \mathrm{CCK}$ LI in the Aplysia CNS. Portions of this work have appeared previously in abstract form (Morgan et al., 1982).

\section{Materials and Methods}

Tissue preparation. A. californica (150 to $300 \mathrm{gm}$ body weight) were obtained from Pacific Biomarine, Inc. and from Marine Specimens, Unlimited, and were maintained in aerated seawater at $15^{\circ} \mathrm{C}$. For immunostaining, dissected tissue samples were fixed for 18 to $24 \mathrm{hr}$ in Bouin's fixative containing $1 \%$ glacial acetic acid. Fixed tissues were dehydrated and embedded in paraplast, and serial $10-\mu \mathrm{m}$ sections were cut and transferred to gelatinized slides. Whole ganglia were serially sectioned; every fourth section was used for a specificity control.

Immunocytochemistry. Immunocytochemical staining was performed by the peroxidase-antiperoxidase (PAP) unlabeled antibody enzyme method (Sternberger, 1979). Antiserum 5135 was raised in a rabbit immunized with synthetic nonsulfated porcine CCK8 conjugated to BSA using glutaraldehyde and is specific for the $\mathrm{COOH}$-terminal pentapeptide common to CCK and gastrin which is the molecular center of biological activity of each peptide. Tissue sections were hydrated and covered with phosphate-buffered saline (PBS; $0.05 \mathrm{M}, \mathrm{pH} 7.6$ ) containing $1 \%$ normal sheep serum which also served as diluent for antisera. Then the sections were treated sequentially with: undiluted normal sheep serum (20 min; room temperature; GIBCO), antiserum 5135 (1:200 to $\left.1: 2000 ; 24 \mathrm{hr} ; 4^{\circ} \mathrm{C}\right)$, sheep anti-rabbit serum $(1: 200 ; 10$ min; room temperature; Cappel), rabbit PAP soluble complex (1:200; $10 \mathrm{~min}$; room temperature; Cappel), and Hankers-Yates reagent $\left(0.15 \%\right.$; Polysciences) with $\mathrm{H}_{2} \mathrm{O}_{2}$ $(0.03 \%$; $5 \mathrm{~min}$; room temperature) in PBS alone. The sections were then dehydrated and mounted in Permount.

Specificity controls. Controls were performed by preabsorbing antiserum 5135 either with 2 to $4 \mu \mathrm{M}$ (15 Leu)synthetic human gastrin 17-I (Research Plus), synthetic porcine CCK8 (Squibb), caerulein (Farmitalia), FMRFamide (Bachem), or $5 \mathrm{mg} / \mathrm{ml}$ of BSA. The structures of the peptides used are shown in Table I. Also, normal rabbit serum was substituted for antiserum 5135 in some tests. Positive control staining was performed using rat antrum and duodenum and Xenopus skin tissue sections processed in parallel with the Aplysia tissues.

Radioimmunoassay. Gastrin/CCK radioimmunoassay
(RIA) was performed as described by Rosenquist and Walsh (1980). Four antisera with similar but not identical specificities for the $\mathrm{COOH}$ terminus of mammalian G/CCK were used. Antisera 5135 and L48 cross-react nearly equally with all forms of gastrin and CCK larger than G/CCK5 because they are specific for the $\mathrm{COOH}$ terminus common among all gastrins and CCKs (Dockray, 1980; Rosenquist and Walsh, 1980). Antiserum 1296 is specific for the mid- to $\mathrm{COOH}$-terminal region of gastrin 17 and, therefore, reacts only weakly with CCKs and G4 (Rosenquist and Walsh, 1980). Antiserum L112 is specific for the common $\mathrm{COOH}$ terminus of CCKs and gastrins and reacts equally with all forms of the peptides, including G4 (Dockray et al., 1981). Antisera L48 and L112 were gifts from Dr. G. J. Dockray, University of Liverpool, antiserum 5135 was a gift from Dr. G. Rosenquist, University of California, Davis, and antiserum 1296 was a gift from Dr. J. H. Walsh, University of California, Los Angeles. The standard used in all assays was (15 Leu)-synthetic human gastrin $17-\mathrm{I}$, and this peptide was also monoiodinated by the method of Stadil and Rehfeld (1972) and used as tracer.

Tissue extraction. To study the distribution of extractable G/CCK-LI, buccal, cerebral, pedal, pleural, and abdominal ganglia as well as hepatopancreas from eight animals were dissected, frozen separately on dry ice, and pooled by tissue for extraction. The tissues were then thawed, extracted in boiling distilled water $(0.1 \mathrm{gm} / \mathrm{ml})$ for $15 \mathrm{~min}$, cooled, and clarified by centrifugation.

To determine the optimal conditions for extraction of Aplysia G/CCK-LI, the buccal, cerebral, pedal, pleural, and abdominal ganglia from six animals were dissected, pooled together, and homogenized. The homogenate was divided into two portions; one was extracted in boiling distilled water $(0.1 \mathrm{gm} / \mathrm{ml})$, and the other was extracted in boiling $0.1 \mathrm{M} \mathrm{NH}_{4} \mathrm{HCO}_{3}, \mathrm{pH}$ 8.2. After centrifugation, the pelleted residue from the boiling water extract was re-extracted in boiling $3 \%$ glacial acetic acid $(0.1 \mathrm{gm} /$ $\mathrm{ml}$ ).

Column chromatography. Sephadex G50 SF (Pharmacia) columns $(1 \times 120 \mathrm{~cm})$ were equilibrated and eluted at $4{ }^{\circ} \mathrm{C}$ with $0.025 \mathrm{M}$ veronal buffer $(\mathrm{pH} 8.6)$ containing $0.02 \%$ sodium azide. Fractions of $1.5 \mathrm{ml}$ were collected at a flow rate of $6 \mathrm{ml} \cdot \mathrm{cm}^{-2} \cdot \mathrm{hr}^{-1}$. Samples were fortified with $2.5 \mathrm{mg}$ of BSA and $\mathrm{Na}^{125}$ I to provide markers for the void and salt volumes, respectively. Column fractions were analyzed by RIA using antisera 5135 , L48, and I.112.

To prepare large amounts of Aplysia CNS G/CCK-LI

TABLE I

Amino acid sequences of (15-Leu)-synthetic human gastrin 17-I, porcine CCK8, frog skin caerulein, and molluscan FMRF-amide aligned from the C terminus

(15-Leu)-syn-human G17-I

Porcine CCK8

Caerulein

FMRF-amide
Glp-Gly-Pro-Trp-Leu-Glu-Glu-Glu-Glu-Glu-Ala-Tyr-Gly-Trp-Leu-Asp-Phe- $\mathrm{NH}_{2}$ $\mathrm{SO}_{3} \mathrm{H}$

Asp-Tyr-Met-Gly-Trp-Met-Asp-Phe- $\mathrm{NH}_{2}$ $\mathrm{SO}_{3} \mathrm{H}$

${ }^{a}$
Glp-Gln-Asp-Tyr-Thr-Gly-Trp-Met-Asp-Phe- $\mathrm{NH}_{2}$

${ }^{a}$ Glp - pyrrolidone carboxylic acid (pyroglutamyl).

${ }^{b}$ Met is the fifteenth residue in natural human (and other species) gastrin. 
for RIA dilution curves, $91 \mathrm{ml}$ of a boiling $0.1 \mathrm{M}$ $\mathrm{NH}_{4} \mathrm{HCO}_{3}(0.1 \mathrm{gm} / \mathrm{ml})$ extract of pooled ganglia were applied to a $5 \times 90 \mathrm{~cm}$ column ( $1800-\mathrm{ml}$ column volume) of Sephadex G50 SF equilibrated in $0.1 \mathrm{M} \mathrm{NH}_{4} \mathrm{HCO}_{3}$. Fractions of $10 \mathrm{ml}$ were collected at a flow rate of 2.3 $\mathrm{ml} \cdot \mathrm{cm}^{-2} \cdot \mathrm{hr}^{-1}$. Column fractions were analyzed by RIA using antiserum L48, and fractions containing G/CCKLI were pooled, lyophilized, and redissolved in a small volume of distilled water.

\section{Results}

All of the ganglia tested except the pleural ganglia contained specifically immunostained somata (Figs. 1 to 3 , Table II). However, the pleural ganglia did resemble the other ganglia in containing specifically immunostained fibers. Replacing immune serum with nonimmune serum or with immune serum preabsorbed with gastrin, CCK, or caerulein always abolished staining (Fig. 1). Bovine serum albumin and FMRF-amide-preabsorbed immune serum did not decrease specific immunostaining.

In specifically stained perikarya, the entire cytoplasm is immunostained and the nucleus remains unstained (Fig. 3). In some sections, processes are observed projecting away from perikarya (Fig. 3). The apparent number of cell bodies per ganglion varied from about 15 in the buccal and abdominal ganglia to about 30 to 50 in the pedal ganglia (the pleural ganglia did not contain immunoreactive perikarya). The number of cell bodies per ganglion agreed closely with the relative amount of G/CCK-LI that could be extracted (Table II). The diameters of immunostained cell bodies varied from about $15 \mu \mathrm{m}$ to about $200 \mu \mathrm{m}$. In most ganglia, somata containing G/CCK-LI were scattered individually or formed small clusters with other similarly immunostained cell bodies.

Specifically immunostained nerve processes were detected in all ganglia, including the pleural ganglia which did not contain G/CCK cell bodies (Table II). The central neuropil was most intensely stained in the abdominal and pedal ganglia (Figs. 1 and 2) and contained a lower percentage of $\mathrm{G} / \mathrm{CCK}$ fibers in the cerehral, buccal, and pleural ganglia. In the abdominal ganglion, the distribution of both G/CCK-LI perikarya and processes was clearly distinct from the distribution of bag cells and egglaying hormone (ELH) processes described by Chiu and Strumwasser (1981). In some sections, G/CCK processes could be observed entering or leaving neuropil regions of ganglia in commissures, connectives, and nerves. G/ CCK-stained processes were not observed to penetrate the vascularized connective tissue sheath of ganglia, again in contrast to ELH processes (Chiu and Strumwasser, 1981).

Some connectives and peripheral nerves were tested. In all interganglionic connectives examined, a fraction of the fibers contained C/CCK-LI (Table II, Fig. 4). When sectioned longitudinally, many G/CCK-stained processes had a beaded appearance.

Immunoreactivity in pooled ganglia was extracted equally well in boiling distilled water and in boiling 0.1 $\mathrm{M} \mathrm{NH}_{4} \mathrm{HCO}_{3}, \mathrm{pH}$ 8.2. The amounts of G/CCK-LI measured by the various antisera were approximately equal in both neutral and alkaline extracts. However, the four antisera differed in their apparent cross-reactivity with Aplysia CNS G/CCK-LI. Potency estimates (G17-I eq) of the water and ammonium bicarbonate extracts of the pooled ganglia were (femtomoles per gram of wet tissue weight): 503 (L48), 132 (1296), <70 (5135), and <930 (L112). Re-extraction of pooled ganglia in boiling acid did not yield detectable G/CCK-LI using any of the antisera. Hepatopancreas extracts did not have detectable G/CCK-LI using any antiserum.

A sample of the boiling ammonium bicarbonate extract of pooled ganglia was fractionated on Sephadex G50-SF (Fig. 5). Eluate fractions were analyzed by RIA using antisera L48, 5135, and L112. Radioimmunoassay using antisera L48 and 5135 revealed similar fractionation profiles and indicated that the major Aplysia CNS G/ CCK-LI is probably a relatively small molecule $\left(K_{\mathrm{av}}=\right.$ 0.76 ). Furthermore, the close correspondence between the fractionation profiles revealed by RIA using antisera L48 and 5135 indicates that the immunocytochemistry (performed with antiserum 5135) and RIA are likely to be measuring the same substances. Antiserum L112 RIA did not detect G/CCK-LI in column eluates.

To perform full range RIA dilution curves for immunological characterization, it was necessary to prepare a large amount of relatively concentrated Aplysia CNS G/ CCK-LI. Fractionation of $91 \mathrm{ml}$ of pooled ganglia extract on Sephadex G50-SF yielded an immunoreactive profile (L48 RIA) essentially identical to that obtained using a smaller column and different eluting buffer (cf. Fig. 5). Lyophilization of the major immunoreactive component eluting in a volume corresponding to an elution constant $\left(K_{\text {av }}\right)$ of 0.76 yielded a preparation concentrated 53 -fold and purified 24-fold (picomoles per $\mathrm{A}_{280}$ ) relative to the crude extract. This partially purified and concentrated fraction gave RIA dilution curves parallel to standard mammalian gastrin 17 using both antisera L48 and 1296 (Fig. 6).

\section{Discussion}

The present findings confirm our previous demonstration of G/CCK-LI in the A. californica CNS (Larson and Vigna, 1983) and further demonstrate the neuronal origin and some immunochemical properties of this activity.

The widespread distribution of G/CCK-LI in the CNS of Aplysia resembles the pattern described for antigastrin immunoreactivity in the pond snail, L. stagnalis (Schot et al., 1981). In both molluscan species, G/CCK-LI is found in most ganglia, connectives, and nerves, and even the relative numbers of G/CCK-LI-containing perikarya per ganglion are very similar. It may be that both pulmonate and opisthobranch molluscs use neuronal G/ CCK-LI similarly.

We have made no attempt to correlate the immunocytochemical staining pattern of G/CCK-LI perikarya with identified cells described previously in the Aplysia CNS (Kandel, 1979) because of uncertainties in the exact orientation of the individual ganglia sectioned. It does appear that when the same ganglion from different individuals is immunostained, similar if not identical cells are revealed. This is especially evident in those ganglia with relatively few G/CCK-LI cells, such as the abdominal ganglion with its four large perikarya present in the 

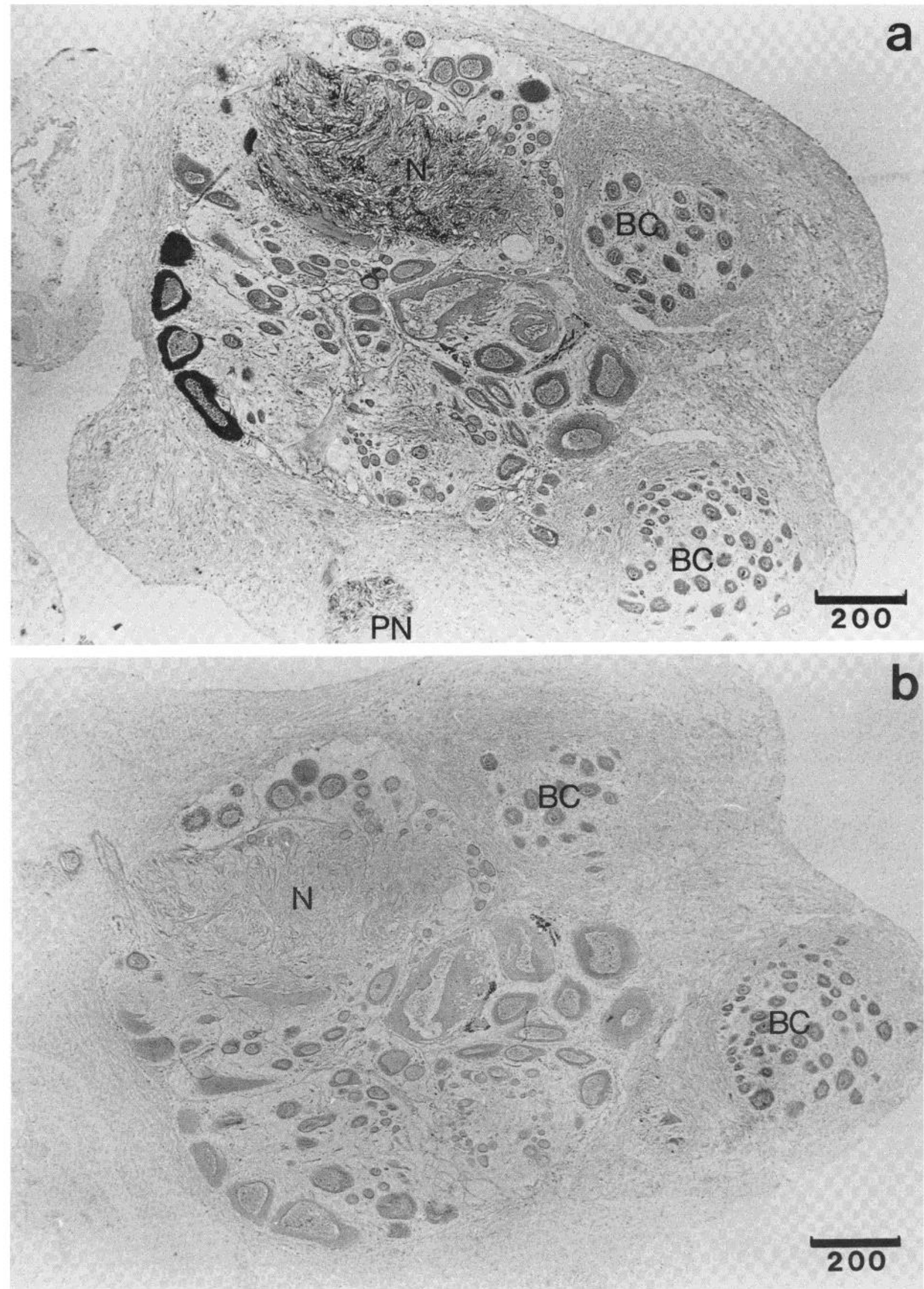

Figure 1. a, Abdominal ganglion with four large G/CCK-LI perikarya in the right caudal quadrant and G/CCK-LI nerve processes in the neuropil $(N)$. The bag cell clusters $(B C)$ are unstained. An unidentified peripheral nerve $(P N)$ exiting the ganglion also contains some specifically stained fibers. $b$, An adjacent specificity control section treated with gastrin-preabsorbed primary antiserum. Scale bar $=200 \mu \mathrm{m}$. 


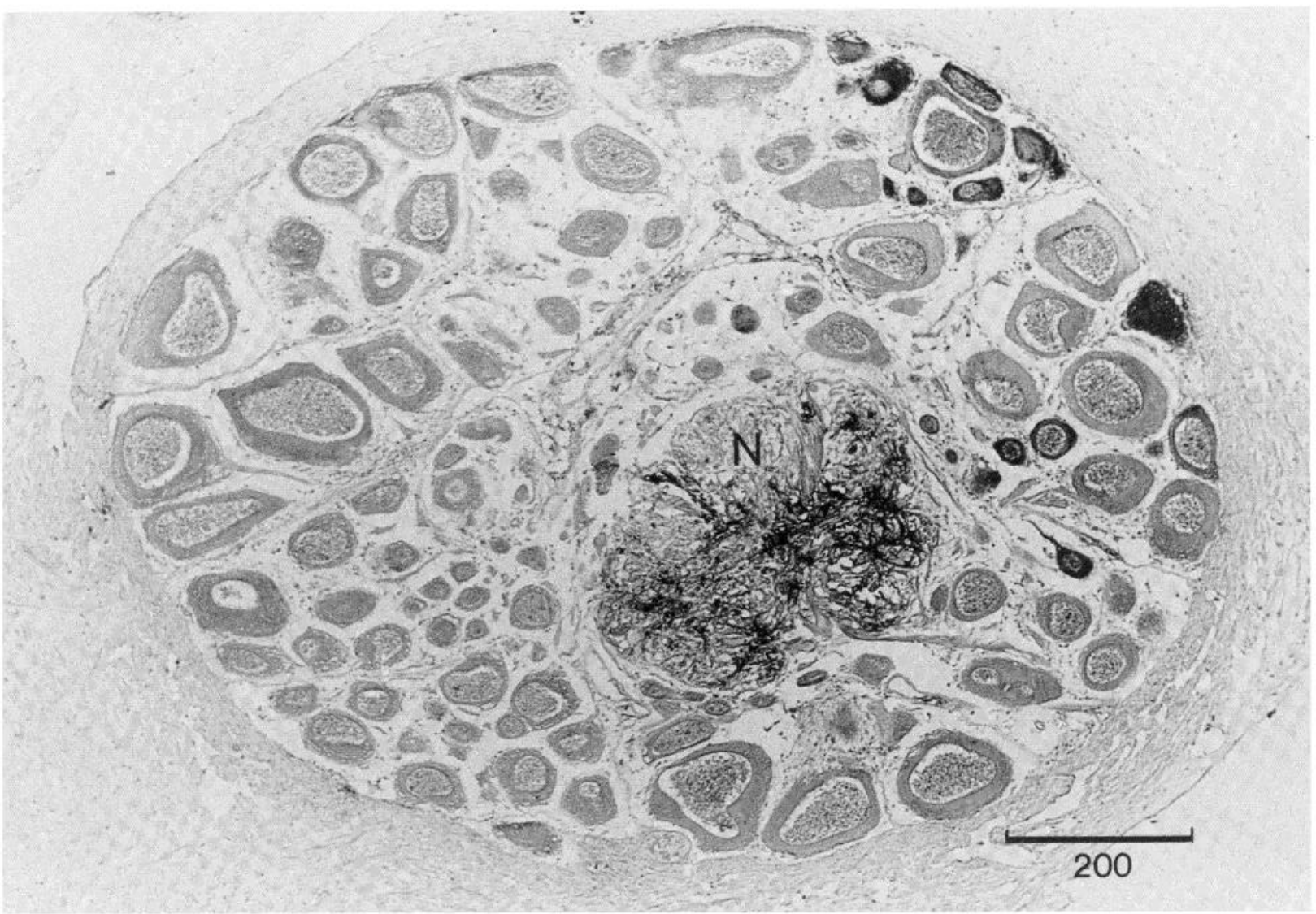

Figure 2. Pedal ganglion with several perikarya containing G/CCK-LI in the caudal region. Dense immunostaining of fibers is present in the neuropil $(N)$. Scale bar $=200 \mu \mathrm{m}$.

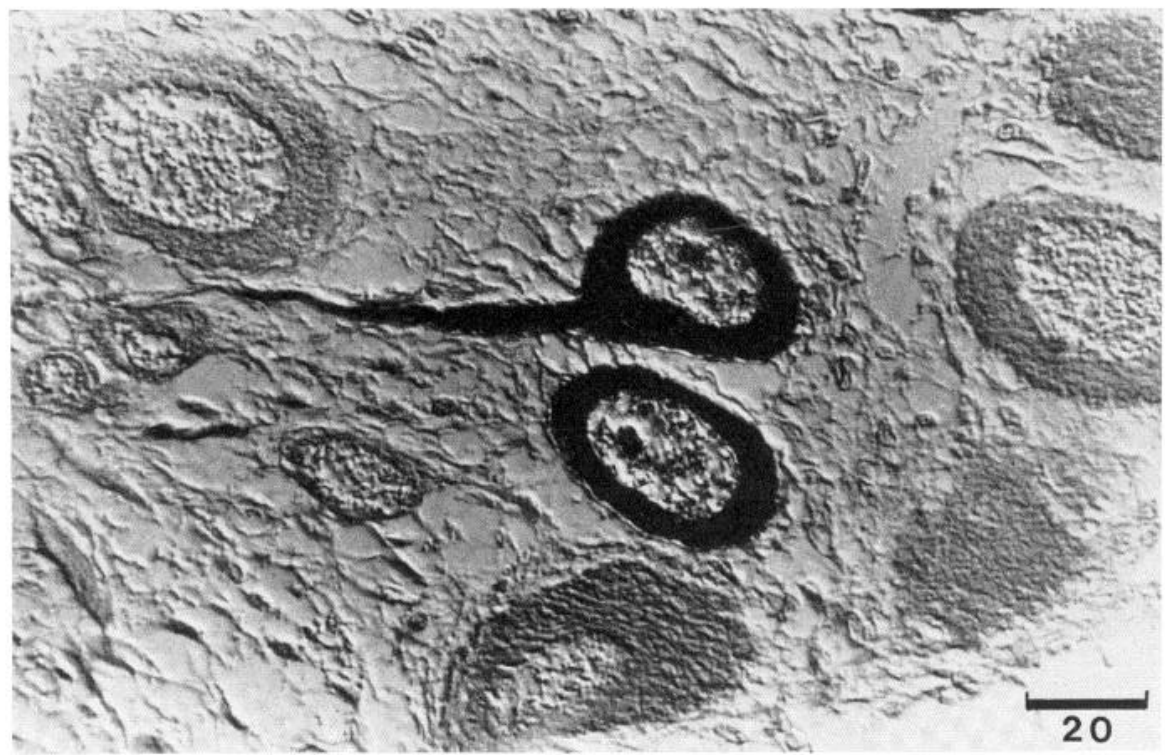

Figure 3. Two G/CCK-LI-containing perikarya and several unstained cell bodies in the cerebral ganglion. The nuclei of the two G/CCK-LI cells are unstained. A G/CCK-LI-filled axonal process can be seen projecting from one cell body toward the neuropil. Nomarski interference. Scale bar $=20 \mu \mathrm{m}$.

right caudal quadrant (cf. Fig. 1). However, it is not yet possible to assign these cells, for example, to the RB cluster of cell bodies described by Frazier et al. (1967).

In future studies it will be extremely useful for several reasons to map carefully the distribution of G/CCK-LI in peripheral nerves emanating from the CNS. The fields of innervation of the major peripheral nerves in Aplysia are well known (Kandel, 1979) and thus provide clues 
TABLE II

Distribution of G/CCK-LI in some parts of the Aplysia nervous system determined by immunocytochemistry and by RIA of tissue extracts

\begin{tabular}{|c|c|c|c|}
\hline \multirow{2}{*}{ Tissue } & \multicolumn{2}{|c|}{ Immunocytochemistry } & \multirow{2}{*}{ RIA $^{a}$} \\
\hline & Somata & Fibers & \\
\hline \multicolumn{4}{|l|}{ Ganglia } \\
\hline Buccal & $+^{b}$ & + & 1010 \\
\hline Cerebral & + & + & 315 \\
\hline Pedal & + & + & 1080 \\
\hline Pleural & - & + & $<100$ \\
\hline Abdominal & + & + & 524 \\
\hline \multicolumn{4}{|l|}{ Connectives } \\
\hline Buccal-cerebral & & + & $\mathrm{NT}^{\mathrm{c}}$ \\
\hline Cerebral-pleural & & + & NT \\
\hline Cerebral-pedal & & + & NT \\
\hline Pleural-abdominal & & + & NT \\
\hline \multicolumn{4}{|l|}{ Nerves } \\
\hline Buccal 3 & & - & NT \\
\hline Pedal 8 & & + & NT \\
\hline Pedal 9 & & + & NT \\
\hline \multicolumn{4}{|l|}{ Other } \\
\hline Eye & - & - & NT \\
\hline
\end{tabular}

${ }^{a}$ Femtomoles per gram of wet weight (gastrin 17-I eq) measured using antiserum L48.

${ }^{b}+=$ specific immunostaining present; $-=$ specific immunostaining absent.

${ }^{\mathrm{c}} \mathrm{NT}=$ not tested.

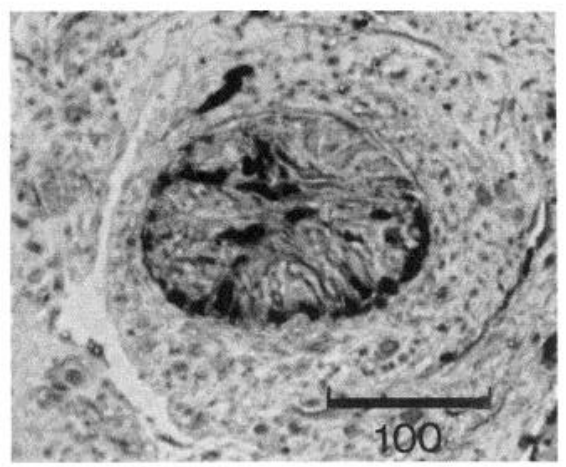

Figure 4. Cross-section of the right buccal-cerebral connective containing several immunostained G/CCK-LI processes, some of which are located at the periphery of the connective adjacent to the connective tissue sheath. Scale bar $=100 \mu \mathrm{m}$.

about the possible physiological targets of G/CCK-LI as a putative neurotransmitter/neuromodulator. It must be remembered also that the peripheral concentration of stainable G/CCK-LI in the buccal-cerebral connective (cf. Fig. 4), for example, suggests a possible neurohormonal role for this peptide in Aplysia because the richly vascularized connective tissue sheath surrounding the nervous system in this species is purported to be a neurohemal organ. Such a mode of action is consistent with the observation of gastrin-like immunoreactivity circulating in the hemolymph of $A$. californica (Straus et al., 1975). Another reason for careful mapping of G/ CCK-LI in peripheral nerves is to compare that distribution with the known innervation of the gut (Kandel, 1979) in order to determine the source of the extensive G/CCK-LI fiber tracts in the gastrointestinal tract and their possible relation to apparent G/CCK-LI perikarya in the gut that we recently described (J. L. M. Morgan, T. M. Thomas, and S. R. Vigna, submitted for publication).

The present finding of more efficient extraction of Aplysia CNS G/CCK-LI in neutral or alkaline rather than acidic solutions agrees with previous findings using Aplysia gut (Straus et al., 1975) and H. aspersa (Osborne et al., 1982). In addition, the fractionation profile on Sephadex G50 of Aplysia CNS G/CCK-LI is similar to that reported for Aplysia and Otala lactea gut and hemolymph (Straus et al., 1975) and H. aspersa CNS (Osborne et al., 1982) extracts. The major component of molluscan G/CCK-LI elutes from such columns in an elution volume corresponding to a peptide of between 8 and 17

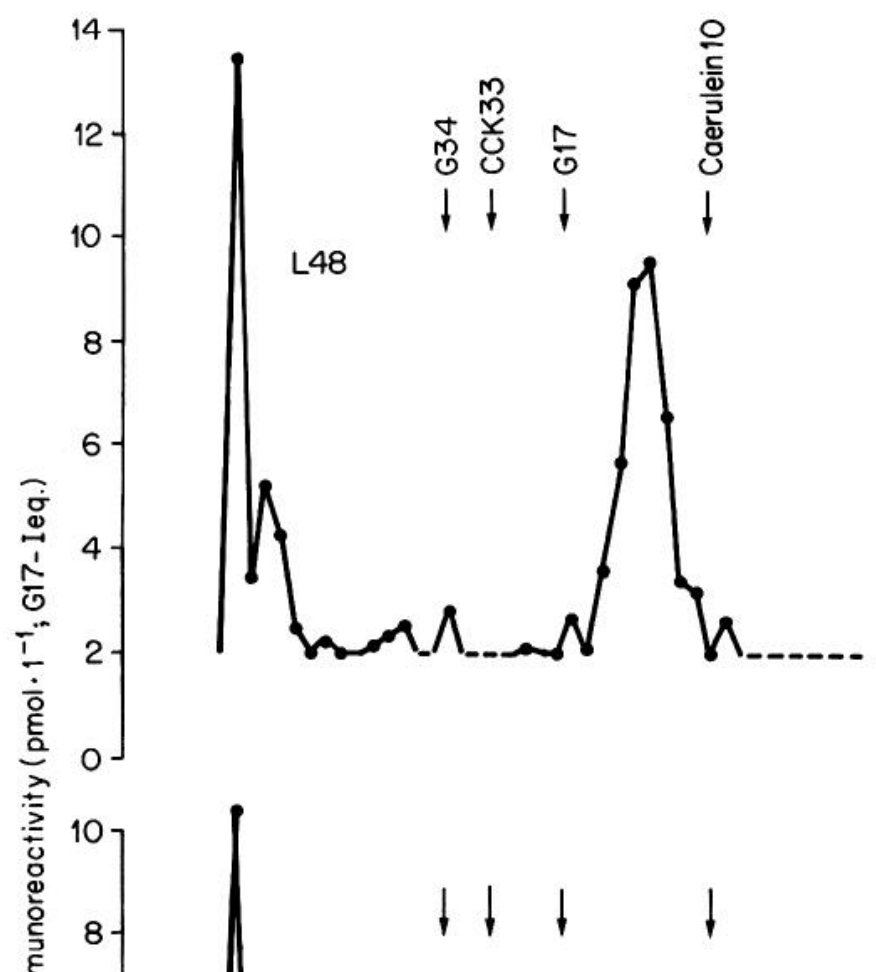

5135

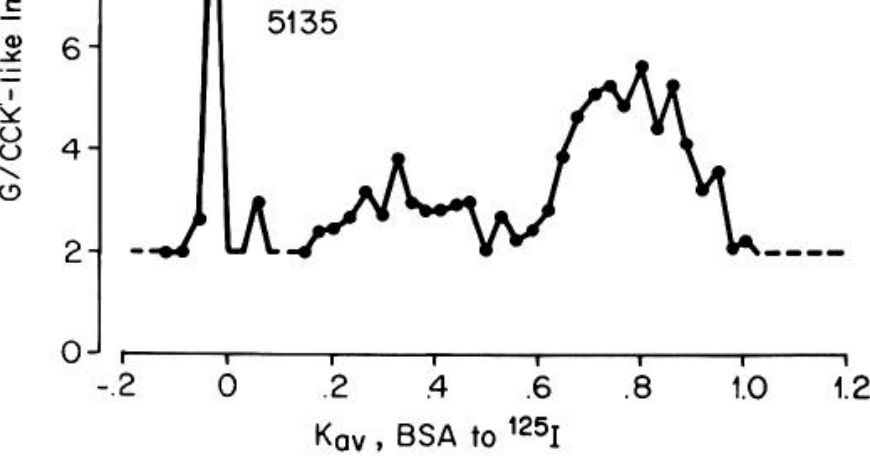

Figure 5. The elution profile of an extract of pooled ganglia on Sephadex G50-SF. G/CCK-LI was measured in eluate fractions by RIA using antisera L48 (upper panel) and 5135 (lower panel). Absorbance at $280 \mathrm{~nm}$ was measured to determine the void volume $\left(K_{\mathrm{av}}=0\right)$, and $\mathrm{Na}^{125} \mathrm{I}$ was added to the sample as a marker of the salt volume $\left(K_{\mathrm{av}}=1.0\right)$ of the column. In separate runs the column was calibrated with gastrin 34 (G34), cholecystokinin $33(C C K 33)$, gastrin $17(G 17)$, and caerulein 10 . 


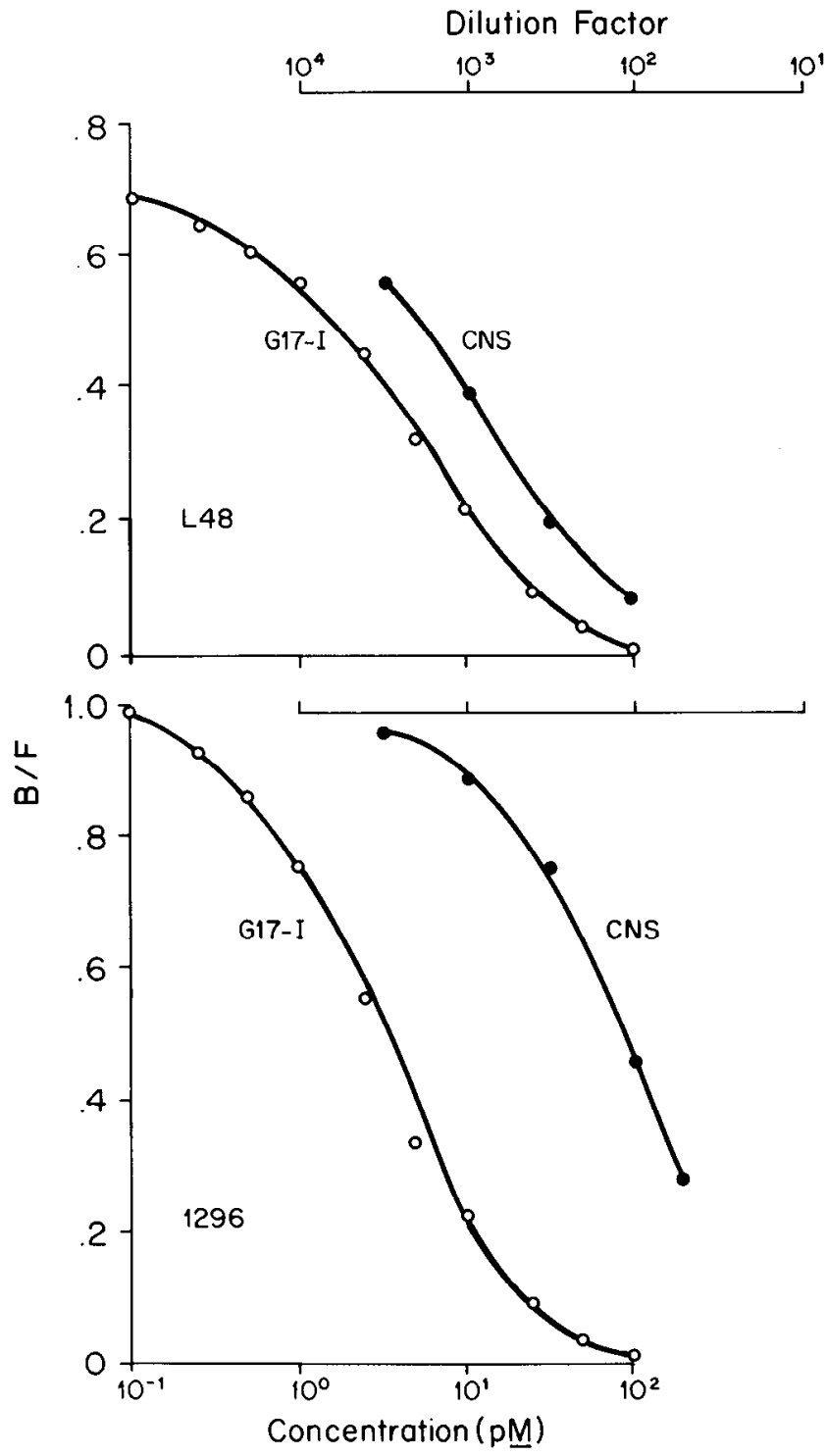

Figure 6. Serial RIA dilution curves of gastrin 17-I and pooled ganglia extract using antisera L48 (upper panel) and 1296 (lower panel). Log concentration of G17-I and reciprocal of dilution (on a logarithmic scale) of the extract are plotted versus bound/free ratio $(B / F)$. Each point represents the mean of duplicate determinations.

residues $\left(K_{\mathrm{av}}=0.7\right.$ to 0.8$)$. Evidence for a somewhat larger molecular component of molluscan G/CCK-ILI ( $K_{\mathrm{av}}=0.4$ to 0.5 ) has also been presented (Straus et al., 1975; Osborne et al., 1982). This component in Aplysia gut extracts is converted to the apparently smaller form by incubation with trypsin (Straus et al., 1975), suggesting a possible precursor-product relationship between the two peptides in vivo. In our hands, some but not all Aplysia CNS extracts exhibit this apparently higher molecular weight form of putative precursor G/CCK-LI. This may be due to physiological differences between groups of animals pooled for tissue extraction, differential conversion during extraction, or other unknown causes.

The immunological determinants of Aplysia G/CCKLI were investigated using several antisera with different specificities for mammalian gastrin and CCK. Using the antiserum (L112) specific for the bioactive $\mathrm{COOH}$-terminal tetrapeptide common to mammalian gastrins and CCKs (G4), we were unable to detect cross-reacting material in Aplysia CNS extracts or gel filtration eluates. This is in contrast to the findings of Osborne et al. (1982) in which antiserum L112 measured higher concentrations of Helix G/CCK-LI than did other antisera. However, antiserum L48, which is directed against a $\mathrm{COOH}$ terminal portion of mammalian G/CCK slightly larger than G4 (Dockray et al., 1981), cross-reacted relatively strongly with Aplysia CNS extracts. These findings suggest that the $\mathrm{COOH}$-terminal tetrapeptide portion of the Aplysia peptide may be somewhat different in structure from mammalian $\mathrm{G} / \mathrm{CCK}$, but that there are some sequence similarities in the adjacent part of the molecule. Interestingly, the strongly gastrin-specific 1296 antiserum appeared to recognize the Aplysia peptide somewhat better than did antiserum 5135, which is very similar in specificity to L48 with respect to the mammalian peptides. This is reminiscent of the findings reported by Straus et al. (1975) that Aplysia gut contains a gastrin-like immunoreactant. In sum, it appears that Aplysia CNS G/CCK-LI is similar to but immunochemically distinguishable (at the functionally critical $\mathrm{COOH}$ terminus) from mammalian gastrins, CCKs, and possibly the Helix CNS peptide, but it may be identical to the previously reported Aplysia gut gastrin-like substance. Isolation and full structural determination are now required to establish the chemical relationships among these peptides.

The tissue distribution and apparent size of the major component of Aplysia CNS G/CCK-LI are reminiscent of previous observations concerning radioactively labeled small peptides in the CNS of Aplysia. The abdominal (Berry and Schwartz, 1977) and the circumesophageal ganglia (cerebral, pedal, and pleural; Berry and Geinisman, 1979) incorporate radioactively labeled leucine into several size classes of proteins and peptides, transport these labeled molecules in various connectives and nerves, and process the larger forms into small peptides during axonal transport. Furthermore, some substances synthesized in the circumesophageal ganglia were shown to be transported to nerve endings in the neuropil of the abdominal ganglion where their secretion could be demonstrated under certain conditions (Berry, 1979). It is not known if G/CCK-LIs are among these peptides, but the possibility that they are is attractive because: $(i)$ the distribution of G/CCK-LI is consistent with the sites of labeled amino acid incorporation and transport; (ii) Aplysia CNS G/CCK-LIs exist as large and small molecular weight species of about the size range demonstrated by Berry and co-workers, and the large form can be converted enzymatically to the small form; and (iii) even though the smaller secreted forms of mammalian gastrins and CCKs do not contain leucine, we have recently characterized a G/CCK-like peptide extracted from another invertebrate, the crab Cancer magister, which does contain leucine in the $\mathrm{COOH}$-terminal region of the molecule (B. A. Larson, S. R. Vigna, J. Reeve, and J. Shively, submitted for publication). Thus, this leucine residue would be expected to be retained in both precur- 
sor and product (secreted) forms of the molecule. The way is now open to evaluate the biosynthesis and release of Aplysia CNS G/CCK-LI.

The physiological role of G/CCK-LI in Aplysia is unknown. Indeed, the same can be said about any animal species, including the common laboratory mammals. Some of the barriers to progress in defining the neurobiological role of $\mathrm{G} / \mathrm{CCK}$ include the complexity of the vertebrate nervous system, the small size of most neurons, and the heterogeneity of brain tissue samples. It seems likely that studies of the accessible, extremely large, and potentially individually identifiable G/CCK cells in the relatively simple and well documented Aplysia CNS may shed some light on the fundamental properties of these neuropeptides.

\section{References}

Berry, R. W. (1979) Secretion of axonally transported neural peptides from the nervous system of Aplysia. J. Neurobiol. 10: 499-508.

Berry, R. W., and Y. Geinisman (1979) Interganglionic axonal transport of neural peptides within the nervous system of Aplysia. J. Neurobiol. 10: 489-498.

Berry, R. W., and A. W. Schwartz (1977) Axonal transport and axonal processing of low molecular weight proteins from the abdominal ganglion of Aplysia. Brain Res. 129: 75-90.

Chiu, A. Y., and F. Strumwasser (1981) An immunohistochemical study of the neuropeptidergic bag cells of Aplysia. J. Neurosci. 1: 812-826.

Dockray, G. J. (1980) Cholecystokinins in rat cerebral cortex: Identification, purification, and characterization by immunochemical methods. Brain Res. 188: 155-165.

Dockray, G. J. (1982) The physiology of cholecystokinin in brain and gut. Br. Med. Bull. 38: 253-258.

Dockray, G. J., R. G. Williams, and W. Zhu (1982) Development of region-specific antisera for the C-terminal tetrapeptide of gastrin/cholecystokinin and their use in studies of immunoreactive forms of cholecystokinin in rat brain. Neurochem. Int. 3: 281-288.

Frazier, W. F., E. R. Kandel, I. Kupferman, R. Waziri, and R. E. Coggeshall (1967) Morphological and functional properties of identified neurons in the abdominal ganglia of Aplysia californica. J. Neurophysiol. 30: 1288-1351.

Kandel, E. R. (1979) Behavioral Biology of Aplysia. A Contribution to the Study of Opisthobranch Molluscs, W. H. Freeman and Co., San Francisco.

Larson, B. A., and S. R. Vigna (1983) Species and tissue distribution of cholecystokinin-gastrin-like substances in some invertebrates. Gen. Comp. Endocrinol. 50: 469-475.

Morgan, J. L. M., T. M. Thomas, and S. R. Vigna (1982) Gastrin/cholecystokinin-like immunoreactivity in the nervous system of Aplysia californica. Am. Zool. 22: 866.

Ondetti, M. A., B. Rubin, S. L. Engel, J. Pluscec, and J. T. Sheehan (1970) Cholecystokinin-pancreozymin: Recent developments. Am. J. Dig. Dis. 15: 149-156.

Osborne, N. N., A. C. Cuello, and G. J. Dockray (1982) Substance $\mathrm{P}$ and cholecystokinin-like peptides in Helix neurons and cholecystokinin and serotonin in a giant neuron. Science 216: 409-411.

Rehfeld, J. F. (1978) Localisation of gastrins to neuro- and adenohypophysis. Nature 271: 771-773.

Rehfeld, J. F. (1980) Cholecystokinin. Trends Neurosci. 3: 6567.

Rehfeld, J. F. (1981) Four basic characteristics of the gastrincholecystokinin system. Am. J. Physiol. 240: G255-G266.

Rosenquist, G. L., and J. H. Walsh (1980) Radioimmunoassay of gastrin. In Gastrointestinal Hormones, G. B. J. Glass, ed., pp. 769-795, Raven Press, New York.

Schot, L. P. C., H. H. Boer, D. F. Swaab, and S. Van Noorden (1981) Immunocytochemical demonstration of peptidergic neurons in the central nervous system of the pond snail Lymnaea stagnalis with antisera raised to biologically active peptides of vertebrates. Cell Tissue Res. 216: 273-291.

Stadil, F., and J. F. Rehfeld (1972) Preparation of ${ }^{125}$ I-labelled synthetic human gastrin I for radioimmunoanalysis. Scand. J. Clin. Lab. Invest. 30: 361-368.

Sternberger, L. A. (1979) Immunocytochemistry, Ed. 2, John Wiley \& Sons, New York.

Straus, E., R. S. Yalow, and H. Gainer (1975) Molluscan gastrin: Concentration and molecular forms. Science 190: 687-689.

Williams, J. A. (1982) Cholecystokinin: A hormone and a neurotransmitter. Biomed. Res. 3: 107-121. 